\title{
Otologic Surgery Training in a Rural Ethiopian Community
}

\author{
Miriam Redleaf ${ }^{*}$, Nega Kiros Hagos², Girma Tessema ${ }^{3}$, Yilikal Zemene Tassew4 ${ }^{4}$. Hanna Hailu Redleaf ${ }^{5}$ \\ ${ }^{1}$ Louis J. Mayer Professor of Otolaryngology, University of Illinois Hospital and Health Sciences System, Chicago, Illinois 60612 USA \\ ${ }^{2}$ Dr. Nega Higher ENT Clinic, Addis Ababa, Ethiopia \\ ${ }^{3}$ Yekatit 12 Hospital ENT Department, Addis Ababa, Ethiopia \\ ${ }^{4}$ Mekele University College of Health Sciences, Mekele, Ethiopia \\ 5University of Illinois Hospital and Health Sciences System, Chicago, Illinois 60612 USA
}

\begin{abstract}
Despite the large number of people needing ear surgery on the African continent, otologic (ear) surgeries are few. However, safe and effective otologic surgeries are attainable via rural Ethiopian otologic surgical camps which also provide training to Ethiopian surgeons: Operations and operative results: A total of 137 otologic surgeries were performed during 4 weeklong surgical camps at a rural hospital in Butajira, Ethiopia. Most patients had large, central perforations, $94 \%$ of the operations were under local anesthesia, 26 patients from the first week's camp returned for follow-up testing. There were no complications of surgery, $83 \%$ of perforations closed completely, and $69 \%$ patients had improved hearing measured by pure tone air and bone audiometry. Trainees' experience: A total of 9 Ethiopian ENT surgeons who had previously lacked operative experience as the primary surgeon performed these operations. Three were already in practice, and 6 were recent graduates. All 3 senior Ethiopian doctors returned to their local sites and now perform otologic surgery there.
\end{abstract}

Keywords: Ear, Developing Countries, Hospitals, rural

\section{Introduction}

Despite Africa's large population, ear disease remains understudied on the continent (McPherson \& Swart, 1997). Otitis media has long been recognized as a significant contributor to hearing loss in Africa (A. D. Olusesi, 2008). Tympanosclerosis has been documented at an $11 \%$ rate in Tanzania (Bastos, Mallya, Ingvarsson, Reimer, \& Andréasson, 1995). There is some question whether ear surgery training on the continent is adequate (Peer \& Fagan, 2012). However, scattered reports of tympanoplasty success range from $71 \%$ (Becker \& Lubbe, 2011) to 80\% (Prescott \& Robartes, 1991) to $92 \%$ (Abiodun Daud Olusesi, Opaluwah, \& Hassan, 2011) and successful collaborations in tympanoplasty surgery have been reported (Wright, Walker, \& Yacoub, 2007).

We present our experience as otologic surgeons serving a rural community in Ethiopia. The patients here were operated on in 4 weeklong sessions at the Grarbet Eye and Ear Hospital in Butajira, Ethiopia. Financial support for the "surgical camps" was from the Grarbet Tehadiso Mahber (administrative arm of the hospital) and Christofell Blinden Mission (a philanthropic organization). All operations were performed by native Ethiopian surgeons who had completed accredited residency programs in Germany and Egypt and by residents and recent graduates from the ENT department at Addis Ababa University. These surgeons were well trained in otologic pathology and surgical theory but they lacked operative experience as the primary surgeon in their surgical training. The patients who returned in follow-up demonstrate an acceptable success rate in a setting requiring little financial support after the initial acquisition of instrumentation.

\section{Methods}

\section{Subjects}

Grarbet Eye and Ear Hospital was the site for 4 weeklong sessions of otologic surgery. Throughout the year, staff at the Hospital had previously identified surgical candidates for the surgical camps. These subjects returned for reexamination the Sundays before the start of each surgical camp. These subjects were from the local area, as well as from as far as 900 kilometers away.

\section{Facilities}

All subjects related their history to the Grarbet staff, received an otoscopic examination of their tympanic membranes, and underwent pure tone audiometry (identifying air and bone thresholds, unmasked and masked, for each ear). Operations were performed under sterile conditions using otomicroscopy, high speed mastoidectomy drills when needed, and otologic microinstruments. After an interval of months, patients returned for interval history, repeat visual examination and repeat pure tone audiometry. Otoscopes, microscopes, drills, audiometers and ear instruments had been previously donated to the Hospital. The cost to the Hospital for each patient's surgery (room and board, supplies, operation) was approximately \$150 USD.

\section{Otologic surgery training}

The otologic training was focused on primarily on increasing operative experience. A full professor of Otology/ Neurotology from the Department of Otolaryngology at the University of Illinois Hospital and Health Sciences System, Miriam Redleaf, was present for all aspects of patient care. Selection of surgical cases on the Sunday preceding the surgical camp was supervised. All conversations with Dr. Redleaf were in English. In the operating theater, Dr. Redleaf was present for every operation, visually monitored the surgical sequences, and scrubbed in at some point in most operations to help. Instruction in the operating theater took the form of instant feedback to clarify what was done well, and what should be done differently. Post-operatively the patients were kept overnight and discharged the next day.

In the morning before surgery, clear specific operative goals were set for each surgeon trainee to focus on for the day. In the evenings each surgeon trainee reviewed the successes and the questions of the day's operations with the attending professor. Throughout each of the 4 weeks every effort was made to support the local surgeons' growth and confidence in otologic surgery. 


\section{Results}

\section{Roster of operations}

One hundred thirty-seven patients (age 12 to 40) underwent operations by 9 Ethiopian otolaryngologists working in the country. Eighty-seven percent of the ears were perforated (119 ears), 28\% had tympanosclerosis (38 ears), 12\% had cholesteatoma (17 ears). Operations were distributed as follows; tympanoplasty-112, ossicular reconstructions12, mastoidectomy/atticotomy- 16, stapedectomy- 3, canalplasty- 1. Ninety-four percent of operations were performed under local anesthesia with sedation.
Decision not to require second (follow-up) visit to Grarbet Hospital

Due to the distance that these relatively impoverished patients had to travel, only 26 patients from the first training session returned for follow up examination and testing. None of the patients had any complications relating to their anesthesia. There were no post-operative infections. There were no instances of facial nerve weakness. When we saw the lack of complications and the burden we were placing on the patients for follow-up, we waived that requirement for subsequent surgical camps.

Table 1. Preoperative and postoperative conditions of 26 ears repaired at a rural hospital in Butajira, Ethiopia: Otologic Surgery Outcomes in Rural Ethiopian Community

\begin{tabular}{|c|c|c|c|c|c|c|}
\hline Patient number: & Age: & Type of operation: & Tympanosclerosis? & TM closed? & Pre-Post PTA: & Subjective hearing: \\
\hline 1 & 14 & Tp & no & no & -5 & Same \\
\hline 2 & 15 & Tp & no & yes & 25 & Better \\
\hline 3 & 16 & Tp & no & yes & 7 & Better \\
\hline 4 & 16 & Tp & no & yes & 27 & Better \\
\hline 5 & 16 & Tp-OCR & yes & yes & -10 & Worse \\
\hline 6 & 17 & Tp & no & yes & -2 & Same \\
\hline 7 & 18 & Tp & no & yes & 12 & Better \\
\hline 8 & 19 & $\mathrm{Tp}$ & no & yes & 28 & Better \\
\hline 9 & 20 & Tp-OCR & no & yes & 6 & Better \\
\hline 10 & 20 & Tp & no & no & -7 & Same \\
\hline 11 & 20 & M & no & yes & 31 & Better \\
\hline 12 & 20 & $\mathrm{Tp}$ & no & yes & 10 & Better \\
\hline 13 & 20 & $\mathrm{Tp}$ & no & yes & 38 & Better \\
\hline 14 & 20 & Tp & no & yes & 22 & Better \\
\hline 16 & 21 & $\mathrm{Tp}$ & no & yes & 21 & Better \\
\hline 17 & 21 & $\mathrm{Tp}$ & yes & yes & 15 & Better \\
\hline 18 & 23 & Tp-OCR & no & no & 17 & Same \\
\hline 19 & 23 & $\mathrm{Tp}$ & no & yes & 15 & Better \\
\hline 20 & 23 & $\mathrm{Tp}$ & yes & yes & 0 & Same \\
\hline 21 & 24 & Tp & no & no & 15 & Same \\
\hline 22 & 25 & M-OCR & no & yes* & 7 & Better \\
\hline 23 & 25 & M-OCR & no & yes & 3 & Better \\
\hline 24 & 25 & OCR & yes & yes* & 9 & Better \\
\hline 25 & 27 & Tp & yes & yes & 12 & Better \\
\hline 26 & 35 & $\mathrm{Tp}$ & no & yes & 24 & Better \\
\hline
\end{tabular}

Tp=Tympanoplasty. M=Mastoidectomy. OCR=Ossiculoplasty.

\section{Surgical results}

Table 1 presents pre and post-operative conditions of these 26 patients' ears.

Pre-operatively, 24 had large, central perforations and 5 had tympanosclerosis. Nineteen patients underwent tympanoplasty only, two patients had mastoidectomies with ossiculoplasty, and three patients underwent tympanoplasty with ossiculoplasty while one patient underwent ossiculoplasty only. Post-operatively 20/24 (83\%) had a closure of their perforations, and 18/26 (69\%) had improved hearing as measured by pre-operative and post-operative pure tone air and bone audiometry (follow up time of 3-12 months). Subjective hearing improvement corresponded to audiometric improvement. Five of the 6 ossiculoplasties (using the patient's own bone instead of a prosthesis) showed improved hearing.

\section{Trainees' experience}

The 3 senior Ethiopian surgeons reported that after their 2 weeklong supervised sessions, they were now performing operations at their local medical facilities. Evaluations were performed on the ENT residents and recent graduates and 2 of the 6 were judged competent to perform underlay tympanoplasties by the end of their weeklong training.

\section{Discussion}

One hundred thirty-seven operations were performed, 94\% were under local anesthesia. Eighty-seven percent had large perforations. Twenty-eight percent had tympanoclerosis. Previous tympanosclerosis had been reported as 11\% in Tanzania (Bastos et al., 1995).

Twenty-six of the patients from the first surgical camp came for a follow up. Previous success rates in African settings in closing tympanic membranes have been reported as 
ranging from 71 to 92\% (Becker \& Lubbe, 2011; Abiodun Daud Olusesi et al., 2011; Prescott \& Robartes, 1991). All our perforations were large, central perforations. Our closure rate was 83\% (20/24), with a follow-up time of 3-12 months (average 8 months). Hearing was improved on 18/26 follow-up audiograms (69\%). Subjective hearing improvement corresponded with audiometric improvement. Ossicular chain reconstruction resulted in improved hearing in 5 out of 6 patients.

All 3 senior Ethiopian surgeons who participated in the first two training camps are now performing otologic surgery at their primary institutions. They each express their confidence in operating on their own. The 6 residents and recent graduates from the ENT department at Addis Ababa University are at varying levels of competence.

This report demonstrates that specialist surgery in the developing world is not a luxury(Wright et al., 2007). The Grarbet Eye and Ear Hospital is supported by its administrative arm (Grarbet Tehadiso Mahber) and receives contributions from the Christofell Blinden Mission, a philanthropic organization. Ethiopian otolaryngologists readily performed these operations under local anesthesia and most perforations closed with improved hearing. The cost to the facility was $\$ 150$ USD per patient. Closure rates of tympanic membrane perforations were higher than those seen in some North American populations (Redleaf, 2014).

From this experience in Ethiopia, programs like this can be inexpensive, beneficial to the population, and provide educational opportunities for the local healthcare providers. The increased confidence and skills of the local surgeons should further the amount of services available to the local population. As the local experience increases, foreign training support will no longer be needed for local healthcare.

\section{Acknowledgements}

The authors would like to thank Grarbet Mahber Tehadiso, a charitable non-profit organization for their continued support of Grarbet Eye and Ear Hospital and Dr. Reddle Tekle Haimanot for his direction and support.

\section{Conflict of interest}

The authors declare that there is no conflict of interest.

\section{Authors' contributions}

NKH performed all post-operative evaluations and audiograms, as well as coordination of the surgical camps. Revised first draft of manuscript.

GT performed tympanoplasties and helped manage surgical camps. Revised first draft of manuscript.

YZT performed tympanoplasties and helped with surgical instruction. Revised first draft of manuscript.

HHR helped with information management.

MR wrote the first draft of the manuscript and incorporated the authors' revisions.

\section{References}

Bastos, I., Mallya, J., Ingvarsson, L., Reimer, A., \& Andréasson, L. (1995). Middle ear disease and hearing impairment in northern Tanzania. A prevalence study of schoolchildren in the Moshi and Monduli districts. International Journal of Pediatric Otorhinolaryngology, 32(1), 1-12.

Becker, J., \& Lubbe, D. (2011). Success rate of myringoplasty at Groote Schuur Hospital. South African Medical Journal = Suid-Afrikaanse Tydskrif Vir Geneeskunde, 101(10), 740.

McPherson, B., \& Swart, S. M. (1997). Childhood hearing loss in sub-Saharan Africa: a review and recommendations. International Journal of Pediatric Otorhinolaryngology, 40(1), 1-18.

Olusesi, A. D. (2008). Otitis media as a cause of significant hearing loss among Nigerians. International Journal of Pediatric Otorhinolaryngology, 72(6), 787-792.

Olusesi, A. D., Opaluwah, E., \& Hassan, S. B. (2011). Subjective and objective outcomes of tympanoplasty surgery at National Hospital Abuja, Nigeria 20052009. European Archives of Oto-Rhino-Laryngology: Official Journal of the European Federation of Oto-RhinoLaryngological Societies (EUFOS): Affiliated with the German Society for Oto-Rhino-Laryngology - Head and Neck Surgery, 268(3), 367-372.

Peer, S., \& Fagan, J. (2012). Do South African universities provide the required training platforms for otolaryngology specialist training? South African Medical Journal = Suid-Afrikaanse Tydskrif Vir Geneeskunde, 102(8), 691-692.

Prescott, C. A., \& Robartes, W. J. (1991). Tympanoplasty surgery at the Red Cross War Memorial Children's Hospital 1986-1988. International Journal of Pediatric Otorhinolaryngology, 21(3), 227-234.

Redleaf, M. I. (2014). Air space reduction tympanomastoidectomy repairs difficult perforations more reliably than tympanoplasty. The Laryngoscope, 124 Suppl 3, S1-13.

Wright, I. G., Walker, I. A., \& Yacoub, M. H. (2007). Specialist surgery in the developing world: luxury or necessity? Anaesthesia, 62 Suppl 1, 84-89. 